\title{
Quality of Life Among Narcotic Anonymous Male Members in Yazd
}

\section{City, Iran}

\author{
Fatemeh Hosseini, ${ }^{1}$ Seyed Mojtaba Yassini Ardekani, ${ }^{1}$ Akbar Kordi, ${ }^{1,}$ Banafshe Farzinrad, ${ }^{1}$ and Morteza \\ Musazadeh ${ }^{2}$ \\ ${ }^{1}$ Research Center of Addiction and Behavioral Sciences, Shahid Sadoughi University of Medical Sciences, Yazd, IR Iran \\ ${ }^{2}$ General Physician, School of Medicine, Islamic Azad University, Yazd, IR Iran \\ "Corresponding author: Akbar Kordi, Research Center of Addiction and Behavioral Sciences, Shahid Sadoughi University of Medical Sciences, Yazd, IR Iran. Tel: +98-3532632004, \\ Fax: +98-3532633555, E-mail: Nikrozhsohi.1972@yahoo.com
}

Received 2015 July 05; Accepted 2015 August 10.

\begin{abstract}
Background: Research evidence suggests that the quality of life (QoL) of substance abusers is seriously low.

Objectives: The aim of this study was to assess domains of QoL in narcotic anonymous (NA) members.

Patients and Methods: In this cross-sectional study, 386 NA members were randomly selected from the city of Yazd, Yazd province, Iran, in 2012. The World Health Organization Quality of Life -Brief Questionnaire was used to assess domain scores of QoL. Data were analyzed using analysis of variance (ANOVA) and LSD test with SPSS software version 17.

Results: The results showed that there was a significant difference between age, marital status, drug type used and length of abstinence with domains of $\mathrm{QoL}(\mathrm{P}=0.001)$.

Conclusions: The findings of the current study show that consistent participation in NA self-help groups can significantly lead to an increase in QoL. Further research is recommended to find out causal relationships between participation in NA and QoL in Iran.
\end{abstract}

Keywords: Quality Of Life, Narcotics, Drug Users

\section{Background}

Substance dependency is a chronic and relapsing disorder that may have negative effects on domains of quality of life (QoL) (1). It is considered as a threatening factor for man's physical, mental, social, and spiritual health (2-5). According to the world health organization (WHO) report in 2012, it is estimated that, between 3.5\% and 7.0\% of the world population (aged 15 - 64) had used an illicit drug at least once in the previous year (6). However, the extent of drug use problem remains stable over time. In addition, access to drug dependency treatment services has been only for one out of six drug users each year. The most frequent substances that have been consumed and causing the highest burden of diseases and drug-related deaths in the world are opiate and opioids (6).

In Iran, in the year 2013, about $2.65 \%$ of the population (aged 15 - 64) is estimated to use opioids, as the most commonly used substance, followed by methamphetamines. Furthermore, about $44.71 \%$ of the users aged under 30 (7).

In recent years, treatment demand has been increased (7), which can reflect a problematic level of substance abuse (6). Regarding the nature of substance dependency there are many interventions for treatment, relapse prevention and harm reduction that impose a high cost to health services and families. One way to reduce those costs is attending to self-help groups (8) (e.g., narcotic anonymous (NA)) as adjunctive treatment $(9,10)$. Narcotic anonymous is a self- help group that is composed of recovering individuals with substance abuse problem. This organization provides a supportive network in which members share experiences about overcoming addiction, living drug-free and productively (11). This is achieved through adherence to traditional 12-step principles, which are based on finding meaning in life $(12,13)$. Quality of life (QoL) has been applied as an important tool for the evaluation of the outcome of substance intervention (5). Quality-of-life evaluation can represent and assess the impact of treatment on patient's social functioning, physical and psychological well-being and environmental and life satisfaction (3). Substance use is not usually the reason for seeking treatment but rather is because of having problem in other life domains (social and legal) (5).

Several studies have proved that QoL status is lower in drug abusers starting treatment as compared with the general population and people suffering other medical illnesses $(2,5)$. Other studies have also revealed that substitution treatment can improve QoL status (14-17).

On the other hand, in a review of literature from 38 articles it is reported that although QoL of opioid-dependent 
individuals is low and participation in substitution treatment had a positive effect on QoL status, long-term effects remain unclear (5).

A few studies conducted in Iran indicated that QoL in the NA members was much better than the individuals under methadone maintenance treatment (MMT) $(18,19)$. Therefore, this study was conducted to address the existing gap in the literature which contains few studies on QoL among NA members in Iran and on the inevitable role of self-help groups (NA) in substance dependency treatment. Furthermore, due to the high level of relapse, increasing costs of substitution treatments, psychological interventions and lack of support from medical insurance companies, addressing this issue in an explorative study can be really significant.

\section{Objectives}

The aim of this study was to assess different domains of QoL in NA members in the city of Yazd, Iran, in 2012.

\section{Patients and Methods}

\subsection{Design and Setting}

This cross-sectional exploratory study was conducted on NA members living in the city of Yazd, Iran, in 2012.

\subsection{Participants and Sampling}

Three hundred and eighty-six individuals consistently participating in NA meetings (weekly at least for one month) who had obtained recovery were selected (for the purposes of this study). Any of the individuals who were under treatment due to medical or psychological disorders were excluded from the study.

In order to collect the data, arrangements were made with the NA service committee and the purposes of this study and confidentiality of their information were stated verbally. The researcher then attended the open-meeting and distributed the questionnaires (anonymous) among the members, which were collected at the end of the meetings. The study followed random sampling technique by which the meeting days were selected randomly for the research purposes.

\subsection{Research Instruments}

The study used the WHO QoL-brief- Persian version, the reliability and validity of which has been measured by the researchers in Iran (Cronbach's alpha more than 0.7) (20). This 26-item questionnaire also included a section seeking participants' demographic information, the drug type used and length of recovery.

\subsection{Statistical Analysis}

The collected data were analyzed using SPSS software version 17. Descriptive statistics was used to show the variables and required statistics. Analysis of variance (ANOVA) was used to determine and compare the correlation between the variables. Two-by-two comparisons were done through the LSD method. P values less than 0.05 were considered statistically significant.

\section{Results}

All of the participants were males with the age range of $17-58$ years (mean age $=33.7 \pm 9$ years), and $35.6 \%$ of them were 30 - 39 years old. Also, $62.5 \%$ of the participants were married. Thirty-two percent had junior and senior high school education levels and $24.1 \%$ had university degrees. Moreover, 26.9\% had passed 36 - 59 months of recovery.

In terms of comparison based on quantitative variable of age, the results of QoL are presented in Table 1 . The results revealed that the mean score of QoL domains among different age groups was significantly different $(\mathrm{P}=0.001)$.

The result of between-group comparisons on environmental domains for 17 - 29 and 30 - 39 aged groups showed no significant difference $(\mathrm{P}=0.30)$. However, all the other age groups showed significant differences in all other domains $(\mathrm{P}=0.001)$.

In terms of the relationship between material status and QoL domains, the results (in Table 2) were also signifi$\operatorname{cant}(\mathrm{P}=0.001)$. The between-group comparisons showed a significant difference between the single and married individuals in physical and psychological domains $(\mathrm{P}=0.001)$.

In social domains, there was a significant difference between single and married individuals as well as single and divorced individuals. As for the environmental domain, also the comparison of married individuals with single ones as well as married individuals with divorced ones showed a significant difference.

It is presented in table 3, the mean score of QoL domains compared with length of recovery proved statistically significant $(\mathrm{P}=0.001)$. The results of between-group comparisons according to this factor showed a significant difference for all the domains. However, only in psychological domain comparisons between 12 - 35 and 36 - 59 months groups were not significantly different $(\mathrm{P}=0.062)$.

Regarding the drug type used, there was a statistically significant relationship between drug type and the mean scores of the QoL domains ( $\mathrm{P}=0.001)$. The between-group comparison showed a significant difference between opioid and all other substance in all domains. The comparison between other substances was not statistically significant.

Finally, no significant relationship was found between the educational level and QoL domains. 
Table 1. Mean Scores of Domains of Quality of Life Based on Age ${ }^{a}$

\begin{tabular}{ccccc}
\hline Domains of QoL & Somatic & Psychological & Social & \\
\hline Age $(\mathbf{y})$ & & & & \\
$17-29$ & $22.42 \pm 4.39$ & $17.48 \pm 3.85$ & $9.64 \pm 2.04$ & $23.81 \pm 3.66$ \\
$30-39$ & $23.77 \pm 3.24$ & $9.07 \pm 3.26$ & $24.24 \pm 3.95$ & $11.74 \pm 1.29$ \\
$40-58$ & $26.48 \pm 4.08$ & $21.88 \pm 3.28$ & 0.001 & $27.99 \pm 2.80$ \\
\hline Pvalue & 0.001 & 0.001 & 0.001 \\
\hline
\end{tabular}

Abbreviations: QoL, quality of life; SD, standard deviation.

${ }^{\mathrm{a}}$ Values are presented as Mean $\pm \mathrm{SD}$.

Table 2. Mean Scores of Domains of Quality of Life Based on Marital Status ${ }^{\mathrm{a}}$

\begin{tabular}{ccccc}
\hline Domains of QoL & Somatic & Psychological & Social & \\
\hline Marital status & & & & \\
Single & $22.42 \pm 4.16$ & $17.60 \pm 3.89$ & $9.22 \pm 2.08$ & $23.83 \pm 3.63$ \\
Married & $24.70 \pm 1.27$ & $19.97 \pm 3.81$ & $10.94 \pm 1.58$ & $10.60 \pm 1.56$ \\
Divorced & $23.56 \pm 3.06$ & $18.85 \pm 3.16$ & 0.001 & $24.07 \pm 3.49$ \\
\hline Pvalue & 0.001 & 0.001 & 0.001 \\
\hline
\end{tabular}

${ }^{\mathrm{a}}$ Values are presented as Mean $\pm \mathrm{SD}$.

Table 3. Mean Scores of Domains of Quality of Life Based on Length of Recovery ${ }^{\mathrm{a}}$

\begin{tabular}{|c|c|c|c|c|}
\hline Domains of QoL & Somatic & Psychological & Social & Environmental \\
\hline \multicolumn{5}{|c|}{ Length of recovery } \\
\hline $1-11$ & $19.35 \pm 3.21$ & $14.86 \pm 2.69$ & $8.62 \pm 1.62$ & $21.35 \pm 1.80$ \\
\hline $12-35$ & $24.24 \pm 4.16$ & $19.76 \pm 2.50$ & $10.45 \pm 1.41$ & $25.10 \pm 2.83$ \\
\hline $36-59$ & $25.61 \pm 3.13$ & $20.53 \pm 3.50$ & $11.16 \pm 1.49$ & $26.23 \pm 3.55$ \\
\hline $60-144$ & $26.83 \pm 3.41$ & $21.89 \pm 2.38$ & $11.57 \pm 1.42$ & $27.71 \pm 3.41$ \\
\hline Pvalue & 0.001 & 0.001 & 0.001 & 0.001 \\
\hline
\end{tabular}

${ }^{\mathrm{a}}$ Values are presented as Mean $\pm \mathrm{SD}$.

Table 4. Mean Scores of Domains of Quality of Life Based on the Type of Drug Use ${ }^{a}$

\begin{tabular}{|c|c|c|c|c|}
\hline Domains of QoL & Somatic & Psychological & Social & Environmental \\
\hline \multicolumn{5}{|l|}{ Type of drug } \\
\hline Opioids & $24.80 \pm 6.43$ & $20.12 \pm 4.10$ & $10.93 \pm 1.64$ & $26.15 \pm 4.19$ \\
\hline Metamphetamine & $23.00 \pm 3.88$ & $17.95 \pm 3.75$ & $9.93 \pm 2.08$ & $23.69 \pm 3.25$ \\
\hline Hashish & $23.84 \pm 3.35$ & $18.89 \pm 2.72$ & $9.91 \pm 1.78$ & $24.28 \pm 2.91$ \\
\hline Drug & $21.87 \pm 3.97$ & $17.90 \pm 2.87$ & $9.71 \pm 1.98$ & $23.65 \pm 3.99$ \\
\hline
\end{tabular}

${ }^{\mathrm{a}}$ Values are presented as Mean $\pm \mathrm{SD}$

\section{Discussion}

This study was conducted to assess the domains of QoL in NA members and examine its relationship with their demographic features, length of abstinence and drug type used.

The results showed that the mean age of the NA members in Yazd city was 33.70 years, which was in accordance with the mean age of the substance-dependent individu- 
als in Iran $(7,21)$ and other countries (2), but less than the mean age of the world NA members (43.40), based on the survey conducted by world NA organization (22).

The majority of the participants were married (62.5\%), which was in accordance with the recent overview of the status of addiction in Iran (63\%), and with other similar reports $(23,24)$.

The educational level of most of the participants was high school and diploma (32.9\%), and $24.1 \%$ of the participants had university education. Compared to the world NA report, $41 \%$ of the members had university education levels; therefore, it seems that fewer NA members in the city of Yazd had university degrees. This difference can be due to addiction being considered a taboo and due to the overall setting of the NA meetings having insufficient privacy and the participants' fear risking their social status, though the meetings are assumed to be settled on anonymity basis.

However, the result that there was no significant relationship between the educational level and QoL domains in this study is in line with the findings of the study conducted in northern Taiwan (15), but inconsistent with other studies (5).

This inconsistency can be explained by the fact that there were not a representative number of participants with university degrees in this study or it can be due to participants' tardy attendance in the programs once under adverse consequences of addiction.

Quality of life in married participants was higher than the single and divorced. On the other hand, the individuals using opioid had a better QoL than those using other substances. These results are also consistent with other studies (25).

Moreover, the results of the current study showed that an increase in the length of recovery results in higher mean scores of domains of QoL, which is compatible with other studies indicating a relationship between an improvement in QoL and factors such as participating in selfhelp groups, providing social support, promoted spiritual aspects, skills of coping with life problems $(9,12,26)$ and reduced stress levels. In the same line, a survey conducted by world NA organization reports that participating in NA meeting results in improved familial and social relationship, job stability and a better education (22).

It should be noted that social and spiritual support that NA members receive from each other is the path towards sustained recovery and finding a new drug - free life style which has an important role in prevention of relapse (27).

As for more specific between-group comparisons, the fact that there was no statistically significant difference between participants aged 17-29 and 30-39 with respect to the environmental domain can be explained here.

The WHO QoL-brief domain assesses facts such as security, living conditions, sufficient income and access to health services. Considering the fact that individuals in Iran usually reach a stable job status, marital status and housing no sooner than about 40 years old, as a result of families economical problems and rising of marriage age in recent years; therefore, it seems that substance use and its adverse consequences has similarly threatened the environmental domain of these two age groups under 40 in this study.

This was consistent with the results of other studies, which found a significant negative correlation between the income group and environmental domains $(2,5)$.

Also, the finding that between-group comparisons of married participants showed that their different domains of QoL are higher than the single and divorced participants can suggest the supportive role of the family, which is also in line with the findings of other studies $(12,28)$.

Another finding of the study as a result of betweengroup comparisons according to the length of recovery showed significant differences between different domains for all recovery groups except psychological domain between 12-35 and 36-59 months groups.

This result can be explained by the participants' sense of belonging and acceptance by their peers in the NA group and hope for a better life in early recovery phase $(29,30)$, which leads to a decrease in negative feelings, hence enhancing the psychological domain factors. This enhancement continues (though not statistically significant) in the middle recovery phase (12 - 35 and 36 - 59 months) where they are taking the 12 steps of NA and still learning a new life style.

However, in the final phase (over 60 months recovery), the psychological domain again enhances significantly which shows the participants reaching the final steps and finding a meaning in life and sense of self-efficiency (26). These findings are consistent with Laudet' findings (31).

The present study had a number of limitations. First, because of its cross-sectional design, causative relations were not inclusive in this study. In addition, since data have been collected based on the self-report method, over report and/or under report might have taken place by the participants. The existing stigma about substance use and sociocultural situation in Iran can support this hypothesis.

Since participants were selected only from Yazd city, a selection bias might have occurred, which can cause problem in generalizing the findings to a broader population. Despite the mentioned limitations, it should be considered that the present study is one of the few studies, which has been conducted to evaluate the QoL among NA members in Iran. The study had a number of strengths for clin- 
icians. The findings highlighted the importance of NA involvement on significant enhancement of QoL over time. Improvement in QoL can raise individuals' hope for those who challenge recovery by participating in NA meetings. The findings can furthermore help clinicians to encourage clients to attend NA, while going through formal interventions simultaneously.

Another important implication of this study can be invitation of NA members to treatment services in order to inform clients about NA. The findings can contribute to identification of predictors of intention to participation and sustained stable recovery. Moreover, there is a critical need for identifying predictors and barriers of participation in NA.

Further research can be recommended to assess the effect of 12-step related activities (such as, working step, having a sponsor, etc) on QoL.

\section{Acknowledgments}

The authors would like to thank all the participants for their kind contribution in this study.

\section{Footnotes}

Authors' Contribution: Fatemeh Hosseini: Design, execution and final approval of the manuscript; Seyed Mojtaba Yassini Ardekani: final approval of the manuscript; Banafshe Farzinrad: preparation of the manuscript; Akbar Kordi: preparation and final approval of the manuscript; Morteza Musazadeh: design and data collection.

Financial Disclosure: There was no funding and support for this research.

Funding/Support: Authors declare that they have no financial interest.

\section{References}

1. Srivastava S, Bhatia MS, Rajender G, Angad S. Quality of Life in Substance Use Disorders. Delhi Psy J. 2009;12(1):114-20.

2. Giri OP, Srivastava M, Shankar R. Quality of life and health of opioiddependent subjects in India. J Neurosci Rural Pract. 2014;5(4):363-8. doi: 10.4103/0976-3147.139986. [PubMed: 25288838].

3. Rouhani S, Kheirkhak F, Salarieh I, Abedi S. Quality of life, its early change and retention in MMT programs in Iran: Evidence for policymakers and service providers. Life Sci J. 2012;9(3):2633-8.

4. Moreira Tde C, Figueiro LR, Fernandes S, Justo FM, Dias IR, Barros HM, et al. Quality of life of users of psychoactive substances, relatives, and non-users assessed using the WHOQOL-BREF. Cien Saude Colet. 2013;18(7):1953-62. [PubMed: 23827899].

5. De Maeyer J, Vanderplasschen W, Broekaert E. Quality of life among opiate-dependent individuals: A review of the literature. Int J Drug Policy. 2010;21(5):364-80. doi: 10.1016/j.drugpo.2010.01.010. [PubMed: 20172706].
6. United National Office on Drugs and Crime. World Drug Report 2014. Vienna: United National Office on Drugs and Crime; 2014.

7. Iran Drug Control Headquarters . Drug Control In 2014. Iran: Iran Drug Control Headquarters; 2014. pp. 43-4.

8. Vederhus JK, Timko C, Kristensen O, Clausen T. The courage to change: patient perceptions of 12-Step fellowships. BMC Health Serv Res. 2011;11:339. doi: 10.1186/1472-6963-11-339. [PubMed: 22171827].

9. Kelly JF. Self-help for substance-use disorders: history, effectiveness, knowledge gaps, and research opportunities. Clin Psychol Rev. 2003;23(5):639-63. [PubMed: 12971904].

10. Vederhus JK, Kristensen O. High effectiveness of self-help programs after drug addiction therapy. BMC Psychiatry. 2006;6:35. doi: 10.1186/1471-244X-6-35. [PubMed: 16928266].

11. Iran Region of Narcotic Ananymous. . Basic Information 2007. pprestige in an egalitarian community. Ethos. 2014;42(4):440-59.

12. Chen G. Social support, spiritual program, and addiction recovery. Int J Offender Ther Comp Criminol. 2006;50(3):306-23. doi: 10.1177/0306624X05279038. [PubMed: 16648385].

13. Lowinson JH. Substance abuse: A comprehensive textbook. 5 ed. United States: Lippincott Williams \& Wilkins; 2011. pp. 523-6.

14. Baharom N, Hassan MR, Ali N, Shah SA. Improvement of quality of life following 6 months of methadone maintenance therapy in Malaysia. Subst Abuse Treat Prev Policy. 2012;7(1):32. doi: 10.1186/1747-597X-7-32. [PubMed: 22853701].

15. Chou YC, Shih SF, Tsai WD, Li CS, Xu K, Lee TS. Improvement of quality of life in methadone treatment patients in northern Taiwan: a follow-up study. BMC Psychiatry. 2013;13:190. doi: 10.1186/1471-244X-13190. [PubMed: 23865898].

16. Maremmani I, Pani PP, Pacini M, Perugi G. Substance use and quality of life over 12 months among buprenorphine maintenance-treated and methadone maintenance-treated heroin-addicted patients. $J$ Subst Abuse Treat. 2007;33(1):91-8. doi: 10.1016/j.jsat.2006.11.009. [PubMed: 17588494].

17. Beygi A. Piritual development, socio-religious performance and quality of life in narcotic anonymous. Knowl Healt J. 2011;6(2):6-12.

18. Beygi A, Farahani MN, Mohammadkhani S. The discriminative comparison of Quality of life and Coping Styles in Narcotic Anonymousand Methadone Maintenance Treatment members.J Jes psycho healt. 2011;5(1):1-11.

19. Salehmoghaddam AR, Kahani HB, Vagheii S, Chamanzari H. Evaluation of detoxified addicts's life quality participating in narcotics anonymous, therapeutic community and who refers to methadone therapy clinics sessions in Mashhad, 2012.J Res Devel Nurs Midw. .

20. Nedjat S, Montazeri A, Holakouie K, Mohammad K, Majdzadeh R. The World Health Organization quality of Life (WHOQOL-BREF) questionnaire: Translation and validation study of the Iranian version. J Sch Pub Heal Instit Pub Heal Res. 2006;4(4):1-12.

21. Zare H, Alipoor A, Aghamohammadhasani P, Nazer M, Mokhtaree M, Sayadi A. Assessment role of participation in narcotic anonymous in opiate dependents during abstinence. Zahedan J Rese Med Sci. 2012;14(9):42-6.

22. Narcotic Ananymous Word Services Inc . Narcotic anonymous 2013 membership survy. Van Nuys, CA USA: Narcotic Ananymous Word Services Inc.; 2013.

23. Behdani F, Hebrani P, Arshadi H. Epidemiological characteristics of patients in methadone maintenance treatment, admitted in hejazi hospital, mashad (1384-1385). QuarJ Fundam Ment Heal. 2007;9:53-9.

24. Hosseini F, Yassini M, Ahmadieh M, Vafaeinasab MR, Kholasezadeh M, Dastjerdi G. Retention rate in methadone maintenance therapy.J Sha Sad Uni Med Sci Heal Serv. 2010;18(3):152-8.

25. Malhotra S, Dhawan A, Prakash B. Social support in treatment-seeking heroin-dependent and alcohol dependent patients. Indian J Med Sci. 2002;56(12):602-6. [PubMed: 14514243].

26. Majer JM, Droege JR, Jason LA. A categorical assessment of 12-step involvement in relation to recovery resources. J Groups Addict Recover. 2010;5(2):155-67. doi:10.1080/15560351003766158. 
27. Vederhus JK, Kristensen O, Laudet A, Clausen T. Attitudes towards 12step groups and referral practices in a 12-step naive treatment culture; a survey of addiction professionals in Norway. BMC Health Serv Res. 2009;9:147. doi:10.1186/1472-6963-9-147. [PubMed: 19674454].

28. Matin BK, Jalilian F, Alavije MM, Ashtarian H, Mahboubi M, Afsar A. Using the PRECEDE model in understanding determinants of quality of life among Iranian male addicts. Glob J Health Sci. 2014;6(6):19-27. doi: 10.5539/gjhs.v6n6p19. [PubMed: 25363110].

29. Shamsalina A, Norouzi K, Fallahi Khoshknab M, Farhoudiyan A. Recov- ery based on spirituality in substance abusers in Iran. Glob J Health Sci. 2014;6(6):154-62. doi:10.5539/gjhs.v6n6p154. [PubMed: 25363097].

30. Nasab MB, Papi H, Rad HK. Comparison of resiliency, life quality and emotional intelligence among addicts, non-addicts and improved people. Inter J On New Trends Edu Lit. 2015;1(1).

31. Laudet AB, White WL. Recovery capital as prospective predictor of sustained recovery, life satisfaction, and stress among former poly-substance users. Subst Use Misuse. 2008;43(1):27-54. doi: 10.1080/10826080701681473. [PubMed: 18189204]. 